\title{
Dynamics of DNA Clogging in Hafnium Oxide Nanopores
}

\author{
Shiyu Li, Shuangshuang Zeng, Chenyu Wen, Laurent Barbe, Maria Tenje, Zhen Zhang, Klas Hjort, \\ and Shi-Li Zhang*
}

Cite This: J. Phys. Chem. B 2020, 124, 11573-11583

Read Online

\section{ACCESS | Lill Metrics \& More | 回 Article Recommendations | S1 Supporting Information}

ABSTRACT: Interfacing solid-state nanopores with biological systems has been exploited as a versatile analytical platform for analysis of individual biomolecules. Although clogging of solid-state nanopores due to nonspecific interactions between analytes and pore walls poses a persistent challenge in attaining the anticipated sensing efficacy, insufficient studies focus on elucidating the clogging dynamics. Herein, we investigate the DNA clogging behavior by passing double-stranded (ds) DNA molecules of different lengths through hafnium oxide $\left(\mathrm{HfO}_{2}\right)$-coated silicon $(\mathrm{Si})$ nanopore arrays, at different bias voltages and electrolyte $\mathrm{pH}$ values. Employing stable and photoluminescent-free $\mathrm{HfO}_{2} / \mathrm{Si}$ nanopore arrays permits a parallelized visualization of DNA clogging with confocal fluorescence microscopy. We find that the probability of pore clogging increases with both DNA length and bias voltage. Two types of clogging are discerned: persistent and temporary. In the time-resolved analysis, temporary clogging events exhibit a shorter lifetime at higher bias voltage. Furthermore, we show that the surface charge density has a prominent effect on the clogging probability because of electrostatic attraction between the dsDNA and the

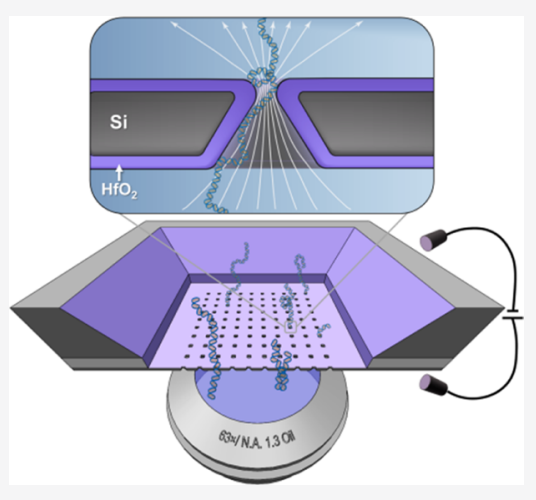
$\mathrm{HfO}_{2}$ pore walls. An analytical model based on examining the energy landscape along the DNA translocation trajectory is developed to qualitatively evaluate the DNA-pore interaction. Both experimental and theoretical results indicate that the occurrence of clogging is strongly dependent on the configuration of translocating DNA molecules and the electrostatic interaction between DNA and charged pore surface. These findings provide a detailed account of the DNA clogging phenomenon and are of practical interest for DNA sensing based on solid-state nanopores.

\section{INTRODUCTION}

Nanopores have emerged as a special class of single-molecule analytical tool that offers immense potential for sensing and characterizing biomolecules such as nucleic acids and proteins. $^{1-3}$ Typically, the nanopore measurement involves applying an external bias voltage to electrophoretically and/or electroosmotically drive biomolecules through nanopores in an insulating membrane. By analyzing ionic current changes, characteristic information of the passing biomolecules is obtained. ${ }^{4}$ An addition to the resistive pulse sensing method is a variety of sensing modalities that solid-state nanopores (SSNPs) can offer, including multicolor discrimination of labeled DNAs and polypeptides, ${ }^{5,6}$ ultrasensitive detection of proteins using nanopore blockade sensors, ${ }^{7}$ optical profiling based on local plasmonic effect, ${ }^{8}$ and selective sensing with nanopore-extended field-effect transistors. ${ }^{9,10}$ Compared to their biological counterparts, the remarkable versatility of SSNPs is due to their wide-range tunability in pore geometries and dimensions as well as mechanical robustness and stability. An added advantage with SSNPs is the compatibility of their fabrication with control electronics as well as optical measurement structures. ${ }^{11-13}$ One major limitation of SSNPs is the nonspecific interaction between biomolecules and their sidewalls, ${ }^{14,15}$ which is an outcome of hydrophobic interaction, $^{16,17}$ electrostatic attraction, ${ }^{18,19}$ and van der Waals forces. $^{20,21}$ These contributing forces can lead to adhesion of biomolecules and clog of the pores, which adversely affect the detection of molecule translocation and the sensing reliability.

To minimize the nonspecific interaction, various coating strategies for SSNPs have been pursued, particularly for sensing proteins and polypeptides, such as employing surfactants, ${ }^{22,23}$ chemical modification via salinization, ${ }^{24}$ selfassembled monolayers of thiols on gold, ${ }^{25,26}$ and coating of the fluid lipid bilayer. ${ }^{27,28}$ While applying organic coatings has proven to be effective on reducing nonspecific interaction, long-term stability and success rate of preparing high-quality organic coatings remain challenging for quantitative and reproducible nanopore experiments. ${ }^{14}$ For DNA sensing, the most common pretreatment of SSNP devices, such as silicon nitride $\left(\mathrm{SiN}_{x}\right)$ SSNPs and glass nanopipettes, is an aggressive chemical cleaning using a mixture of $\mathrm{H}_{2} \mathrm{SO}_{4}$ and $\mathrm{H}_{2} \mathrm{O}_{2}$ to render a hydrophilic surface for unperturbed translocation. ${ }^{29,30}$ However, under the continuous passage of considerable

Received: August 25, 2020

Revised: November 20, 2020

Published: December 14, 2020 
amounts of DNA molecules during the measurement, the tendency to interact with pore walls can still lead to occasional DNA clogging in the pore. Direct observation based on fluorescence microscopy of double-stranded DNA (dsDNA) clogging in $\mathrm{SiN}_{x}$ pores of 5.8 and $100 \mathrm{~nm}$ in diameter has been demonstrated. ${ }^{31,32}$ Lately, it has also been found that circular dsDNA is more prone to clog than linear dsDNA of similar length in relatively large nanopores of 100 and $200 \mathrm{~nm}^{33}$ These results from aforementioned studies were conducted by repeated optical observation of DNA clogging using single nanopores, which conveys a rather limited amount of data to deepen the understanding. Further, little effort has been dedicated to investigating the DNA clogging phenomenon on sub-20 nm pores, the size that is relevant for converting DNA translocation signals to useful information about the DNA sequence. In short, a detailed understanding of the clogging mechanism of DNA molecules and the governing experimental factors is still lacking. All this motivates the present work to systematically investigate the DNA clogging behavior in sub-20 $\mathrm{nm}$ nanopores by direct optical observation, especially focusing on its dependence on DNA length, applied voltage, and surface charge.

The corresponding experimental design should be based upon a nanopore device that enables a reliable and quantitative recognition of DNA clogging events. Even though $\mathrm{SiN}_{x}$ nanopores are widely used to perform electrical sensing of DNA molecules, the $\mathrm{SiN}_{x}$ membrane produces significant photoluminescence (PL) under illumination in the blue-green spectrum range, thereby limiting its applicability in optical sensing. ${ }^{6,34}$ Furthermore, a number of publications have reported that $\mathrm{SiN}_{x}$ and silicon $(\mathrm{Si}) /$ silicon dioxide $\left(\mathrm{SiO}_{2}\right)$ pores suffer from slow erosion during the measurement, which originates from $\mathrm{SiO}_{2}$ in pore walls being dissolved into salt solutions. ${ }^{35-37}$ A variety of experimental factors can affect the etch rate of this erosion process, including salt concentration, temperature, $\mathrm{pH}$ value, and applied voltage. ${ }^{36-39}$ Under certain conditions, for example, high applied voltage or high salt concentration under continuous operation, the etch rate can be sufficiently fast to result in a noticeable pore expansion and uncertainty in quantitative experiments. Recently, coating of $\mathrm{SiN}_{x}$ by hafnium oxide $\left(\mathrm{HfO}_{2}\right)$ and fabrication of $\mathrm{HfO}_{2}$ pores has been demonstrated as an effective solution to preventing pore expansion for long-term measurements or repeated usage. ${ }^{37,40-42}$ Additionally, an $\mathrm{HfO}_{2}$ coating layer is readily wettable and can be easily prepared by means of atomic layer deposition (ALD), making it a promising coating strategy for SSNP sensors.

In this study, we employ an optical sensing platform with $\mathrm{HfO}_{2}$-coated $\mathrm{Si}$ nanopore arrays to investigate the DNA clogging phenomenon by means of confocal fluorescence microcopy (see Figure S1 in the Supporting Information). The employment of $\mathrm{HfO}_{2} / \mathrm{Si}$ nanopore arrays enables a high signalto-background ratio (SBR) in optical readout for the identification of clogging events and allows for multiple usage of the extended measurements with preserved pore geometry. In addition, using SSNP arrays greatly improves the detection throughput via parallelized visualization. An important advantage is that the clogging probability of dsDNA for various DNA lengths, applied voltages, and solution $\mathrm{pH}$ values can be examined real time. Finally, an analytical model is developed by considering both the energy landscape along the DNA translocation trajectory and probable
DNA configurations in order to assist our understanding of the experimental results.

\section{METHODS}

Nanopore Array Fabrication. Nanopore array chips were fabricated from a double-side polished silicon-on-insulator wafer with a $55 \mathrm{~nm}$ thick $\mathrm{Si}$ device layer and a $150 \mathrm{~nm}$ thick buried $\mathrm{SiO}_{2}$ layer. After standard wafer cleaning, a $30 \mathrm{~nm}$ thick low-stress $\mathrm{SiN}_{x}$ layer was deposited on both sides using lowpressure chemical vapor deposition. As a hardmask, the front $\mathrm{SiN}_{x}$ layer was first patterned with nanopore arrays by means of electron beam lithography (EBL) and reactive ion etching (RIE). Next, large cavities were etched in the substrate from the rear side of the wafer by a combination of deep RIE and $\mathrm{KOH}$ etching (at $80{ }^{\circ} \mathrm{C}$ ) to stop on the buried oxide layer (BOX) with the front side of the wafer protected. A second $\mathrm{KOH}$ etching (at $30{ }^{\circ} \mathrm{C}$ ) was then performed to transfer the patterned nanopores in the $\mathrm{SiN}_{x}$ hardmask to the Si device layer. The anisotropic etch of $\mathrm{Si}$ in $\mathrm{KOH}$ solution resulted in a truncated pyramidal shape of nanopores. After the removal of the exposed BOX layer and the top $\mathrm{SiN}_{x}$ hardmask using hydrofluoric acid etching and RIE, respectively, truncatedpyramidal nanopore arrays were formed in the free-standing silicon membrane. Finally, the nanopore arrays were coated with a $5 \mathrm{~nm}$ thick $\mathrm{HfO}_{2}$ by means of ALD.

Optical Setup and Image Analysis. A customized PEEK fluidic cell chamber was made, which allowed the mounted nanopore chips to be illuminated and fluorescence signals in the nanopore region to be collected. A pair of pseudo reference $\mathrm{Ag} / \mathrm{AgCl}$ electrodes was mounted in the electrolyte-filled chambers to apply the external bias voltage. The bottom of the cell chamber was sealed using a $0.17 \mathrm{~mm}$ thick cover glass thereby allowing for a short working distance in optical observation. The optical observation was conducted using a confocal laser scanning microscope (TCS SP8, Leica) with a hybrid GaAsP detector for improved sensitivity of the fluorescence. For all measurements, the fluorescence data were acquired using an HC PL APO $63 \times$ glycerol objective $(\mathrm{NA}=1.3$, Leica $)$ under a $532 \mathrm{~nm}$ laser excitation. Images were processed and analyzed by using Fiji/ImageJ software.

DNA Preparation. DNA ladders with various lengths of 1 $\mathrm{kbp}, 5 \mathrm{kbp}, 10 \mathrm{kbp}$, and $20 \mathrm{kbp}$ were purchased from Fisher Scientific. TOTO-1, an intercalating fluorescent DNA dye, was used to label the DNA molecules with a nucleotide to dye ratio of 10:1. A final $100 \mathrm{pM}$ concentration of labeled DNA was added to a $100 \mathrm{mM} \mathrm{KCl}$ solution.

\section{RESULTS AND DISCUSSION}

Nanopore fabrication and the effect of $\mathrm{HfO}_{2}$ coating will be first presented. Clogging will then be characterized by its behavior and dynamics. This is followed by the presentation of probable effects of the surface charge on clogging. A phenomenological model is proposed to account for the observed clogging phenomenon.

Characterization of $\mathrm{HfO}_{2}$-Coated Si Nanopore Arrays. In order to manufacture $\mathrm{HfO}_{2}$-coated nanopore arrays dedicated to fluorescence detection, we developed a waferscale fabrication method based on a previously established process. ${ }^{43,44}$ The fabrication process is described in detail in the Methods section, and a step-by-step process flow is provided in Figure S2 in the Supporting Information. Briefly, the process consists of two major parts: (1) fabrication of $\mathrm{Si}$ 

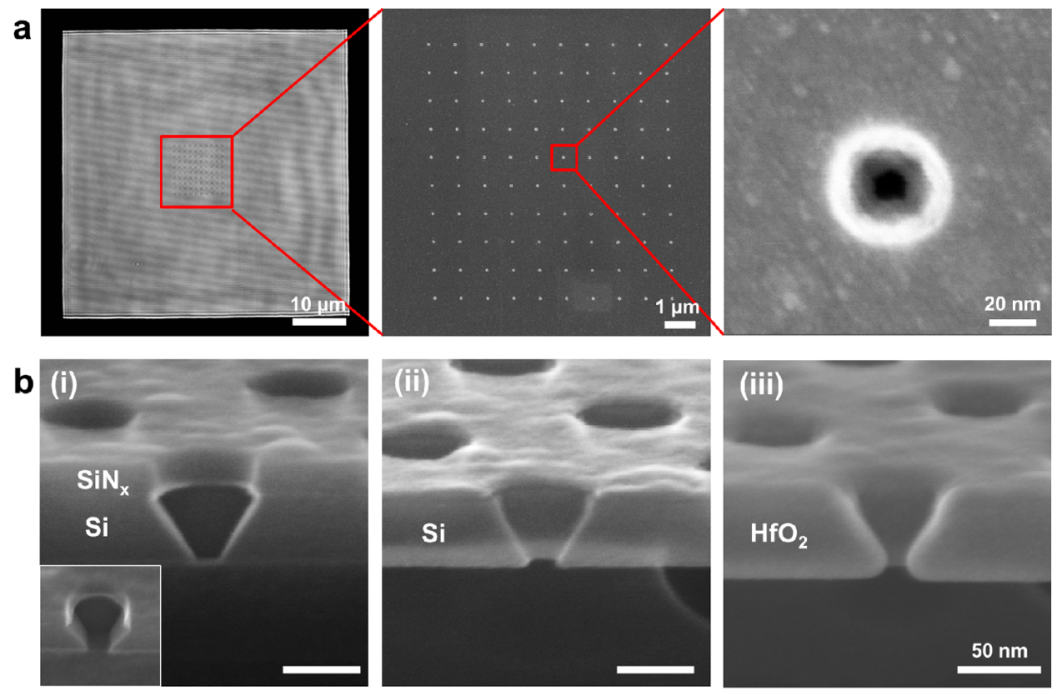

$\mathbf{C}$
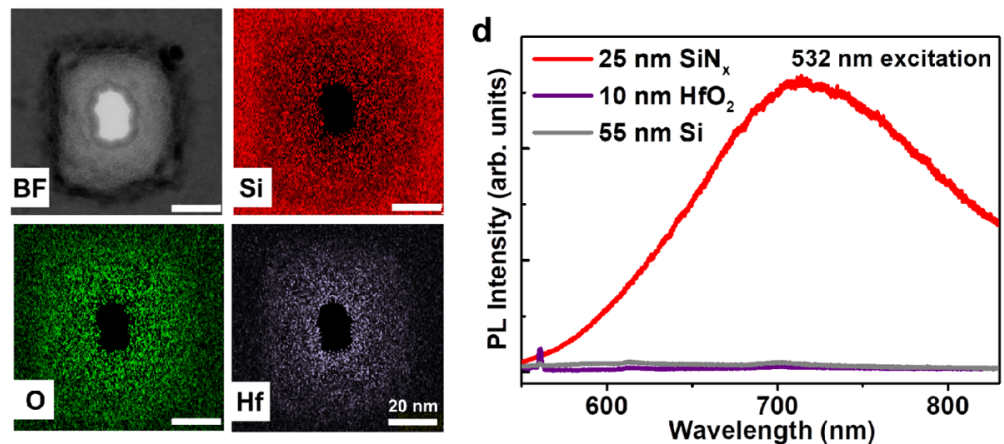

Figure 1. Characterization of $\mathrm{HfO}_{2}$-coated Si nanopore arrays and PL property of relevant membranes. (a) (left) Optical bright field micrograph of the free-standing $\mathrm{HfO}_{2} / \mathrm{Si}$ membrane with a nanopore array located in the center; (middle) SEM image of the 10-by-10 nanopore array with a pore spacing of $1 \mu \mathrm{m}$ in left; (right) top-view SEM image of a single pore with the diameter of its bottom opening around $15 \mathrm{~nm}$. (b) Cross-sectional SEM images of the nanopore structure at different fabrication steps: (i) as-formed and before the removal of the $\mathrm{SiN}_{x}$ hardmask, the nanopore possesses a truncated pyramidal shape. The inset is obtained with a $45^{\circ}$ tilted viewing angle; (ii) after the removal of the $\mathrm{SiN}_{x}$ layer by means of RIE. The image shows a tolerable over-etch resulting in a slightly concaved interior of the Si nanopore; and (iii) after ALD of a $5 \mathrm{~nm}$ thick conformal $\mathrm{HfO}_{2}$ layer. The nanopore arrives at a funnel-like shape. (c) TEM image of the $\mathrm{HfO}_{2} / \mathrm{Si}$ nanopore and EDX mapping images of the

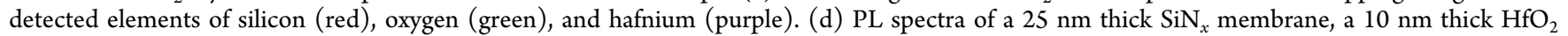
membrane, and a $55 \mathrm{~nm}$ thick Si membrane under an excitation wavelength of $532 \mathrm{~nm}$.

nanopore arrays utilizing EBL and anisotropic etching of Si and (2) removal of the $\mathrm{SiN}_{x}$ hardmask with RIE followed by $\mathrm{HfO}_{2}$ coating by means of ALD.

The bright-field image of a free-standing $\mathrm{HfO}_{2} / \mathrm{Si}$ membrane is shown in Figure 1a (left). A nanopore array is in fact located in the center of this view field. The nanopore array that is visible in the transmission mode of white light facilitates its localization during the optical measurements. Scanning electron microscopy (SEM) images display a well-defined 10-by-10 nanopore array with a pore spacing of $1 \mu \mathrm{m}$ in Figure 1a (middle) and a single nanopore with its bottom opening diameter of approximately $15 \mathrm{~nm}$ in Figure 1a (right). Corresponding cross-sectional SEM images in Figure $1 \mathrm{~b}$ demonstrate the evolvement of nanopore shape at different steps along the fabrication process: (i) the initial Si pore in the truncated-pyramidal geometry resulting from the anisotropic etching of the $\mathrm{Si}$ crystal in $\mathrm{KOH}$ solutions, ${ }^{43}$ with the size of its bottom opening determined by the combination of the top opening size and the membrane thickness; (ii) a slightly concaved interior of the Si pore caused by the RIE for removal of the PL-generating $\mathrm{SiN}_{x}$ mask layer; and (iii) the conformal 5 $\mathrm{nm}$ thick $\mathrm{HfO}_{2}$ coating of the nanopore resulting in a homogeneously shrunk pore with a rounded corner.
Nonuniformity in pore size across a nanopore array persists, though not severe. It mainly results from the EBL step when defining the predesigned nanoscale windows in the $\mathrm{SiN}_{x}$ hardmask. It could be slightly amplified when transferring the windows to the $\mathrm{SiN}_{x}$ layer by $\mathrm{RIE}$ and further to the underlying $\mathrm{Si}$ layer by $\mathrm{KOH}$ etching. Process variations as well as nonuniformity with ALD are usually negligible. For instance, the diameter of bottom openings in a typical nanopore array after the conformal $\mathrm{HfO}_{2}$ coating measures $15 \mathrm{~nm}$ with a standard deviation of $3 \mathrm{~nm}$ (see Figure S3 in the Supporting Information). The geometry and elemental composition of the $\mathrm{HfO}_{2}$ nanopores were further corroborated using transmission electron microscopy (TEM) and energy-dispersive X-ray spectroscopy (EDX) analysis. The bright-field TEM image in Figure 1c shows the top opening of the pore (with a rounded rectangular shape), which is obviously transferred from an elliptical window in the $\mathrm{SiN}_{x}$ mask caused by the occasional deflection of the electron beam during EBL writing. The quantitative EDX mapping images in Figure 1c show the 2D spatial composition of the three involved elements with a detection limit of 0.5 at. \%. The Si signature (red) is strong from the surrounding membrane and starts decreasing from the top edge of the pore. Conversely, the EDX maps of $\mathrm{Hf}$ 

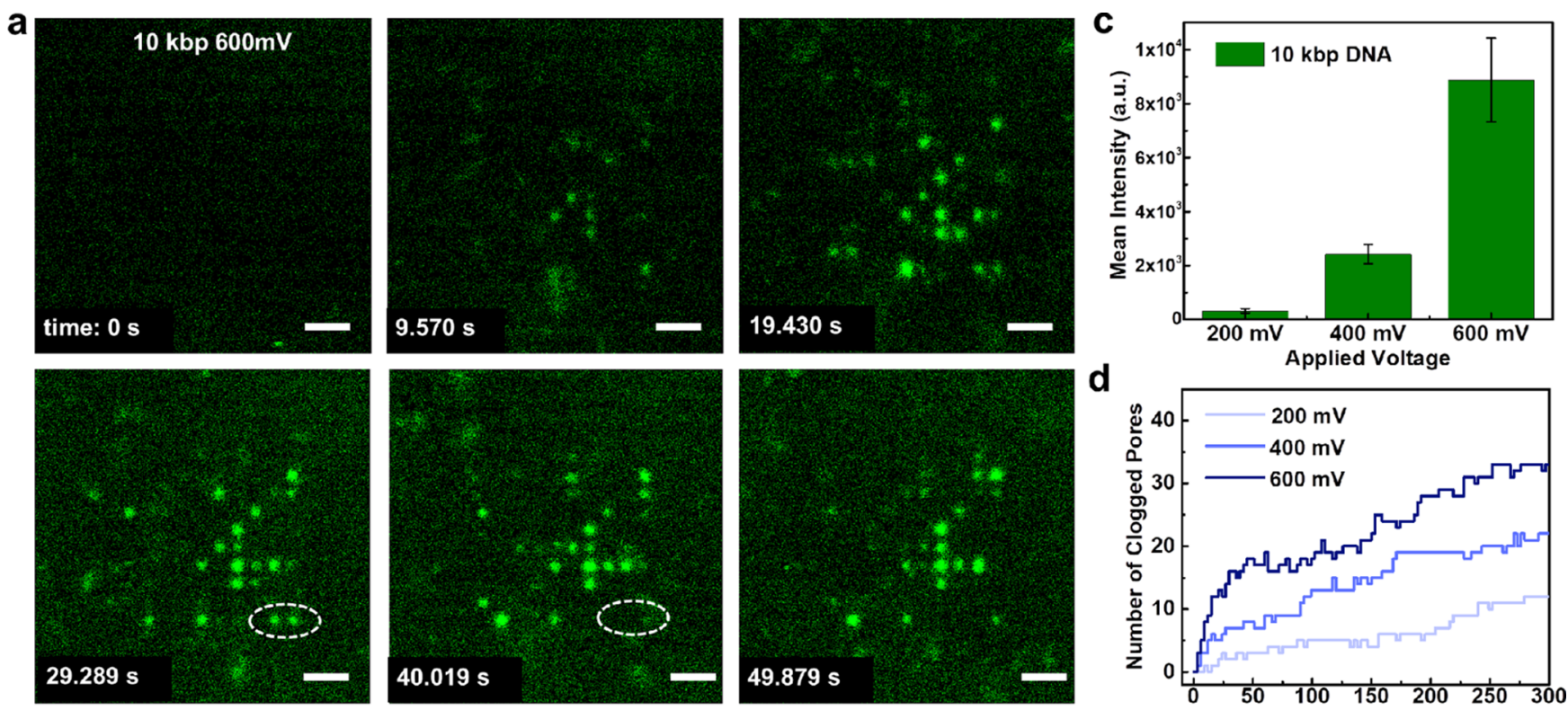

d
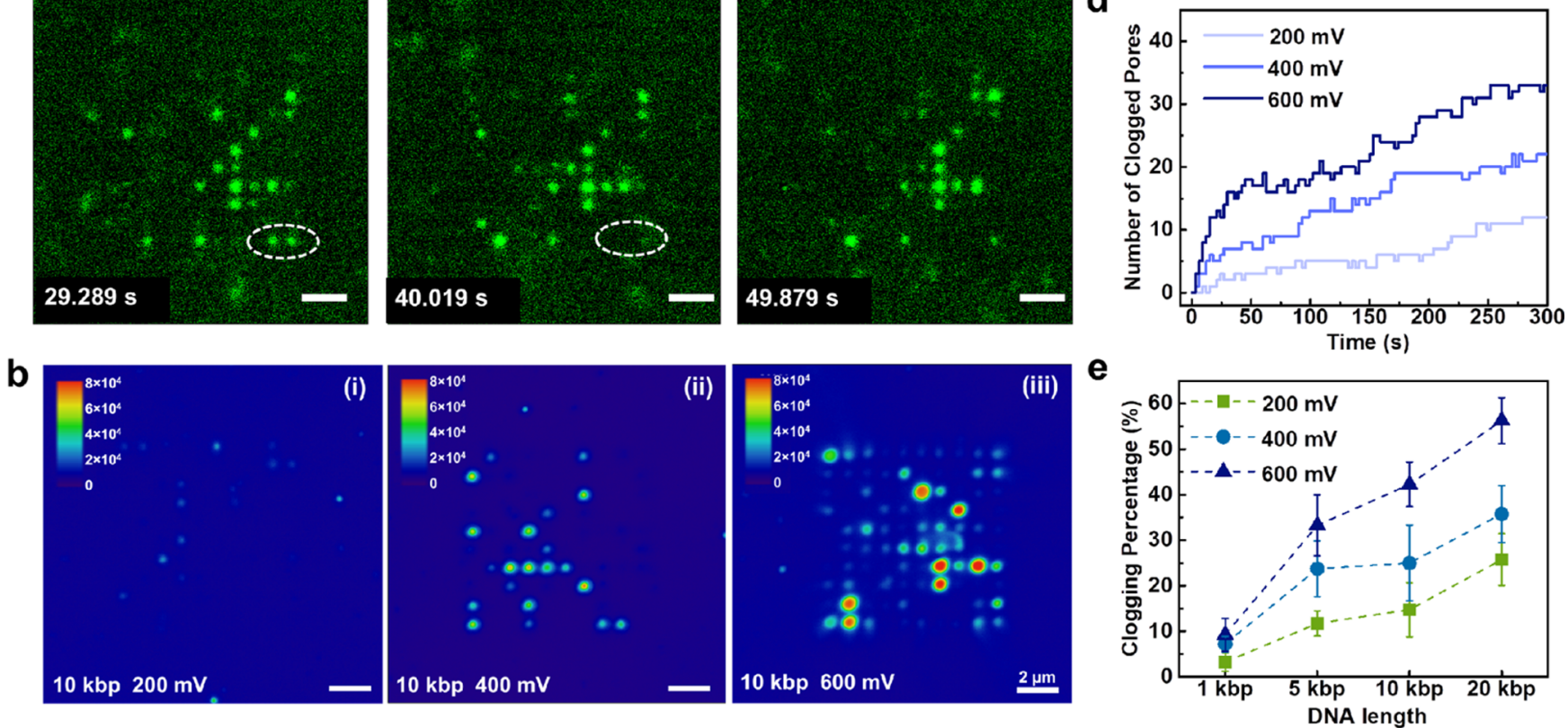

Figure 2. Behavior of DNA clogging in $\mathrm{HfO}_{2}$-coated nanopore arrays. (a) Fluorescence frames of the $10 \mathrm{kbp}$ dsDNA clogged nanopore array biased at $600 \mathrm{mV}$. Images are extracted from a real-time recording for $300 \mathrm{~s}$ at $3.45 \mathrm{fps}$ frame rate. The white dashed ovals mark two pores that are released from clogging by comparing with the respective state in the previous frames. Scale bar: $2 \mu \mathrm{m}$. (b) Images showing the integrated fluorescent signals from 1034 frames (taken in $300 \mathrm{~s}$ ) for the $10 \mathrm{kbp}$ dsDNA molecules at the pore positions at 200 (i), 400 (ii), and $600 \mathrm{mV}$ (iii). The color scales are set identical and coincide with the intensity range of the integrated gray scale. (c) Mean intensity of the integrated fluorescence signals at different bias voltages in the region of pore positions obtained from (b). (d) Plots of the number of clogged pores by the $10 \mathrm{kbp}$ dsDNA molecules vs time at different bias voltages. The clogging state is evaluated every $3 \mathrm{~s}$. (e) Statistical results of the clogging percentage for $1 \mathrm{kbp}, 5$ $\mathrm{kbp}, 10 \mathrm{kbp}$, and $20 \mathrm{kbp}$ dsDNA measured at 200, 400, and $600 \mathrm{mV}$. The clogging percentage is extracted from the last frames at the end of the 300 $s$ recording. Mean values and standard deviations from four independent experiments are presented.

(purple) and $\mathrm{O}$ (green) display a gradual increase in atomic percentage along the radius of the pore toward the center. Hence, the $\mathrm{HfO}_{2}$ layer has shown to conformally cover the truncated-pyramidal Si pore and the results EDX are consistent with the SEM data.

In our studies, PL of the membrane is detrimental because it degrades the SBR and impedes the recognition of singleclogged DNA molecules, particularly for short-length DNA with relatively weak fluorescence. To evaluate the PL emission of the as-fabricated $\mathrm{HfO}_{2} / \mathrm{Si}$ membrane and to compare it to the widely used $\mathrm{SiN}_{x}$ membrane, the $\mathrm{PL}$ spectrum of the following three different membranes was recorded under excitation at $532 \mathrm{~nm}$ : a $25 \mathrm{~nm}$ thick $\mathrm{SiN}_{x}$ membrane, a $10 \mathrm{~nm}$ thick $\mathrm{HfO}_{2}$ membrane, and a $55 \mathrm{~nm}$ thick Si membrane. These different membrane materials were all prepared with the same methods as used in our nanopore device fabrication. The $\mathrm{SiN}_{x}$ membrane exhibits an intense and broad PL emission in the range of 550-830 $\mathrm{nm}$ in Figure 1d. In contrast, the $\mathrm{HfO}_{2}$ and $\mathrm{Si}$ membranes produce negligible $\mathrm{PL}$ in the same wavelength range. Hence, the removal of the $\mathrm{SiN}_{x}$ mask layer in the fabrication process is a prerequisite to render a PL-free membrane. The stark difference is attributed to the large band gap of amorphous $\mathrm{HfO}_{2}(5.8 \mathrm{eV})^{45}$ and the small indirect band gap of $\mathrm{Si}(1.11 \mathrm{eV}),{ }^{46}$ both minimizing the light absorption in the blue to green spectrum range. While previous reports have demonstrated the potential of using titanium oxide $\left(\mathrm{TiO}_{2}\right)^{6}{ }^{6}$ PL suppressed $\mathrm{SiN}_{x},{ }^{34} \mathrm{Si}^{47}$ and $\mathrm{SiO}_{2}{ }^{48}$ membranes for sophisticated optical nanopore sensing, hereon, we note that $\mathrm{HfO}_{2}$ represents to be a further promising candidate material for such a purpose. In addition, the high chemical stability of $\mathrm{HfO}_{2}$ is vital for retaining constant pore geometry.

DNA Clogging Behavior in Nanopore Arrays. All the clogging observations in this work were performed on nanopore arrays with an average diameter of $15 \mathrm{~nm}$. To examine the DNA clogging behavior and take advantage of the array form of pores, real-time visualization of DNA clogging in nanopore arrays was performed using confocal fluorescence microscopy. A customized fluidic cell was made to perform the optical observation (see Figure S4 in the Supporting Information). Different lengths of dsDNA molecules ranging from $1 \mathrm{kbp}$ to $20 \mathrm{kbp}$ were labeled with TOTO-1 fluorescent dye and prepared with a final concentration of $100 \mathrm{pM}$ in $\mathrm{KCl}$ 

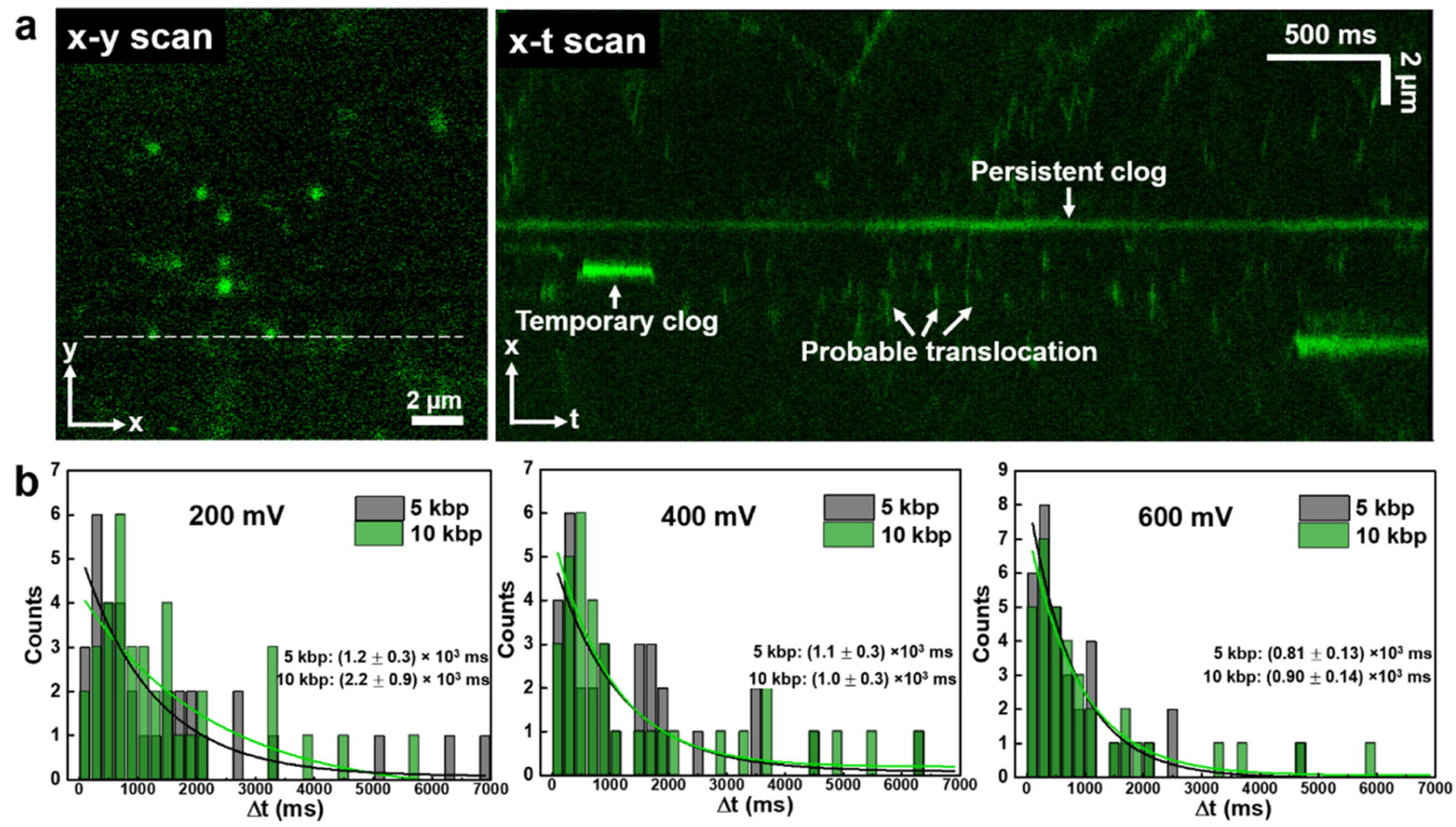

Figure 3. Time-resolved study of temporary clogging of DNA $\mathrm{HfO}_{2}$ nanopore arrays by confocal $x-t$ scans. (a) Fluorescence images of pore clogging acquired by an $x-y$ scan (left) and an $x-t$ scan (right). The white dashed line in the $x-y$ scan marks a row of nanopores that is scanned in the $x-t$ scan mode. In the $x-t$ scan image, the horizontal dimension represents the temporal evolution, where the length of the clogging fluorescent signal denotes the lifetime. The scanning rate of the $x-t$ scan is $0.56 \mathrm{~ms} /$ line. The white arrows mark the typical events that can be observed by an $x-t$ scan: persistent clogging, temporary clogging, and probable translocation of DNA. (b) Histograms of the temporary clogging lifetime of $5 \mathrm{kbp}$ and $10 \mathrm{kbp}$ dsDNA at 200, 400, and $600 \mathrm{mV}$. Curve fitting of the histograms with an exponential function is marked as solid lines, with the fitting parameters given in the figures. Each set of data is analyzed from over 30 clogging events.

solution ( $\mathrm{pH}=7$ ) (details found in Methods). DNA molecules were injected in the top cis chamber and were electrophoretically/electroosmotically driven across the membrane from the small opening side of the pore under an external bias voltage. The focal plane of the objective lens was set on the trans side of the membrane to detect the fluorescent signals from the clogged DNA molecules under a $514 \mathrm{~nm}$ laser excitation. The imaging frame rate to record the clogging phenomenon was 3.45 frames per second. To evaluate the clogging events, the nanopore with residing DNA molecules for more than two sequential frames (over $290 \mathrm{~ms}$ ) was defined as being clogged because the expected translocation time of DNA molecules with such length scale has been reported to be below $2 \mathrm{~ms}$ under similar experimental conditions. ${ }^{49}$ Occurrence of two individual translocation events captured by two consecutive frames is unlikely to be mistaken as a clogging event in our measurement because less than 1 translocation event per second is expected for individual pores according to the translocation frequency study on similarly sized single pores under comparable experimental conditions. ${ }^{49}$

A series of fluorescence micrographs are depicted in Figure $2 \mathrm{a}$ to visualize how the $10 \mathrm{kbp}$ dsDNA molecules clog in a 10by- 10 nanopore array at a $600 \mathrm{mV}$ transmembrane voltage. At $t$ $=0 \mathrm{~s}$, the $600 \mathrm{mV}$ bias is applied and no localized DNA molecules can be observed in the nanopore region. With passing the DNA molecules through the SSNP array, some of the nanopores become clogged as the displayed fluorescent signals remain constant in Figure 2a. Noticeably, some pores can become declogged and an example is marked by the two dashed white ovals, obviously a temporary clogging case. The clogged pores can also show varying fluorescence intensity as a result of single pores being accreted by multiple DNA molecules, in accordance to previous studies. ${ }^{31,32}$ Three time-integrated fluorescence images are shown in Figure $2 b$, each representing the accumulated signals from 1034 frames obtained in a $300 \mathrm{~s}$ recording. The difference in the clogging extent of the $10 \mathrm{kbp}$ DNA is observed under different voltage biases. At a bias voltage of $600 \mathrm{mV}$, a large number of the pores exhibit strong integrated intensity, which can be interpreted as a result of the long-time occupation of DNA molecules in the nanopores and the pores are blocked by multiple DNA molecules. In contrast, only a few pores display discernible integrated intensity in the same color scale at the $200 \mathrm{mV}$ bias. The degree of clogging is further analyzed by extracting the mean intensity in the nanopore region from the timeintegrated images. This mean integrated intensity is found in Figure $2 \mathrm{c}$ to be significantly higher at $600 \mathrm{mV}$ than that at 200 or $400 \mathrm{mV}$, indicating a stronger tendency of DNA molecules residing in the nanopores at higher bias voltage. The number of clogged pores is found in Figure $2 \mathrm{~d}$ to grow with time, and the growth appears to be faster at higher bias voltage. The clogging level is evaluated every $3 \mathrm{~s}$ by comparing with the previous frames. Three video clips showing the evolvement of fluorescence signals for the $10 \mathrm{kbp}$ dsDNA at different bias voltages are included in the Supporting Information.

To further assess the effect of bias voltage and DNA length on pore clogging, a quantitative analysis of the clogging probability is performed. The percentage of clogging is 
evaluated at the end of $300 \mathrm{~s}$ recordings. Results of four independent experiments are taken into statistical analysis for each data group. A monotonous increase in clogging percentage with DNA length is evident in Figure 2e, irrespective of bias voltage, which is consistent with previous reports with larger nanopores $(100$ and $200 \mathrm{~nm}){ }^{33}$ The bias dependence of clogging is found weaker for the $1 \mathrm{kbp}$ dsDNA than for the longer counterparts. In the used bias range, the clogging percentage is below $10 \%$ for the $1 \mathrm{kbp}$ dsDNA, whereas it reaches 30,40 , and $56 \%$ for the $5 \mathrm{kbp}, 10 \mathrm{kbp}$, and $20 \mathrm{kbp}$ dsDNA, respectively. Such high clogging probabilities can pose a serious concern for long-term nanopore-based DNA sensing.

It is widely accepted that DNA clogging during the translocation through SSNPs is caused by the nonspecific interaction between DNA molecules and the pore walls. For small nanopores with the diameter comparable to the dsDNA cross-section diameter $(2.2 \mathrm{~nm})$, DNA-pore interactions govern the DNA translocation process and as a result contribute to a linearized threading configuration with an extended dwell-time distribution. ${ }^{50,51}$ However, for nanopores with diameters several times the dsDNA cross-section, the translocation dynamics is weakly influenced by the DNA-pore interactions for translocation in the linear form. ${ }^{50}$ With our nanopores with an average diameter of $15 \mathrm{~nm}$, lengthy DNA strands can enter with complex molecular configurations, for example, coils, ${ }^{33}$ multiple folding, or knots, ${ }^{53}$ in addition to the simple and ideal linear shape. Such specific configurations have been well-characterized using similar-sized pores in previous studies. $^{52-54}$ The knotting probability of linear dsDNA molecules is experimentally shown to rise with the DNA length, for example, a $13.2 \%$ knotting probability is found for $20.7 \mathrm{kbp}$ DNA molecules probed with $20 \mathrm{~nm} \mathrm{SiN}$ nanopores. ${ }^{53}$ Similarly, for DNA strands of longer length, it is relatively favorable in configurational entropy to translocate with folded configurations because of a higher number of conformation choices compared to shorter DNA. Hence, the observed high probability of clogging occurrence as well as the dependence of clogging probability on DNA length is likely induced by the translocating DNA molecules assuming the aforementioned complex configurations. This hypothesis can be rationalized by considering that the tendency of folded or knotted DNA molecules sticking to the pore surface is higher because of an increased area of interaction and a shortened distance between each DNA segment and pore walls. As for the voltage dependence of clogging probability, it can be attributed to the difference in translocation frequency. The translocation of dsDNA molecules in large SSNPs follows a linear dependence of translocation frequency on voltage and is dominated by a barrier-free capture process. ${ }^{55}$ Translocations of a $15 \mathrm{~nm}$ nanopore by dsDNA of $5 \mathrm{kbp}, 10 \mathrm{kbp}$, and $20 \mathrm{kbp}$ lengths exhibit a length-independent translocation frequency in $1 \mathrm{M} \mathrm{KCl}$ electrolyte, which is linked to a drift-dominated transport process. ${ }^{49}$ As our measurements are performed using $15 \mathrm{~nm}$ SSNPs in $100 \mathrm{mM} \mathrm{KCl}$ solution, the translocation frequency is expected to be linearly dependent on the applied voltage and independent of the DNA length. Hence, it is reasonable to ascribe the observed increasing clogging probability with voltage to an increased translocation frequency.

Time-Resolved Temporary Clogging Behavior. To investigate the temporary clogging events, the $x-t$ scan mode provided by the confocal microscope was employed to acquire fine time-resolved images. The $x-t$ scans were implemented with a resonant $1.8 \mathrm{kHz}$ laser scanner to monitor a row of nanopores in the array, as shown in Figure 3a (left), enabling a temporal resolution of $0.56 \mathrm{~ms}$ to record the local fluorescence variations. Each row consists of 10 nanopores by design, and they are, therefore, simultaneously monitored. The representative $x-t$ scan image of $10 \mathrm{kbp}$ dsDNA translocating the pores at $400 \mathrm{mV}$ displayed in Figure 3a (right) clearly shows a temporary clogging event with a fluorescence span in the temporal dimension of $283 \mathrm{~ms}$ as well as persistent clogging of the pore in the middle of the column. Probable DNA translocation events could also be captured by benefiting from the sub-millisecond scan resolution, as noted in Figure 3a. However, such signals cannot be determined unambiguously as DNA translocation events because flying-by or entry-failed DNA molecules might result in similar signals. Nonetheless, clogging events with substantially longer duration times than translocation events can be readily distinguished in the $x-t$ scan. Thus, the photoluminescent-free $\mathrm{HfO}_{2} / \mathrm{Si}$ membrane is a prerequisite because only a high SBR allows for a reliable identification of DNA signals out of the noisy data collected by single line scanning.

To further characterize the temporary clogging behavior, $x-$ $t$ scan measurements for $5 \mathrm{kbp}$ and $10 \mathrm{kbp}$ dsDNA at different voltage biases were performed. All the probable translocation events are characterized by an optical dwell-time less than 30 $\mathrm{ms}$, which is longer than the reported electrical dwell-time less than $2 \mathrm{~ms}$ under similar conditions. This is expected because DNA molecules with a diffusive motion in the vicinity of a nanopore can still be detected optically while the strong electrical field that determines the electrical sensing range is spatially confined in a much smaller volume. Thereupon, temporary clogging events are defined as fluorescence occurring at pore positions for longer than $60 \mathrm{~ms}$, thereby separating them from the probable translocation events with a large margin. Histograms of the lifetime of over 30 temporary clogging events for each DNA length and voltage are plotted in Figure $3 \mathrm{~b}$, wherein the characteristic clogging time scales and the errors are extracted by curve fitting with an exponential function. As can be seen, the observed temporary clogging events occur in a time span of $7000 \mathrm{~ms}$, with the majority of the events having a lifetime below $2000 \mathrm{~ms}$. Notably, with the increase of the applied voltage from 200 to $600 \mathrm{mV}$, the characteristic clogging time for $5 \mathrm{kbp}$ and $10 \mathrm{kbp}$ dsDNA decreases from $(1.2 \pm 0.3) \times 10^{3} \mathrm{~ms}$ and $(2.2 \pm 0.9) \times 10^{3} \mathrm{~ms}$ to $(0.81 \pm 0.13) \times 10^{3} \mathrm{~ms}$ and $(0.90 \pm 0.14) \times 10^{3} \mathrm{~ms}$, respectively. Declogging of DNA is likely caused by external forces exerting on the unstably clogged DNA molecules. Two of the forces are (i) electrophoretic force on the strongly negatively charged DNA and (ii) dragging force induced by the electroosmotic flow (EOF). For instance, the observed release of T4 DNA (166 kbp) back to the cis chamber after clogging a $100 \mathrm{~nm} \mathrm{SiN}_{x}$ pore was attributed to a dragging force induced by EOF. ${ }^{33}$ With negatively charged pore walls, the EOFinduced force is known to oppose the electrophoretic force. On the contrary, the near-neutral or positive-charged $\mathrm{HfO}_{2}$ surface at $\mathrm{pH} 7$ (see later), as the isoelectric point of $\mathrm{HfO}_{2}$ is $7-8,{ }^{56}$ is expected to induce an EOF force that reinforces the electrophoretic force exerting on the clogged DNA molecules. Therefore, the observed temporary clogging events with our $\mathrm{HfO}_{2}$ SSNPs are most likely ended with DNA translocating to the trans chamber under the combined action of EOF and electrophoresis. Because both the velocity of EOF and the 

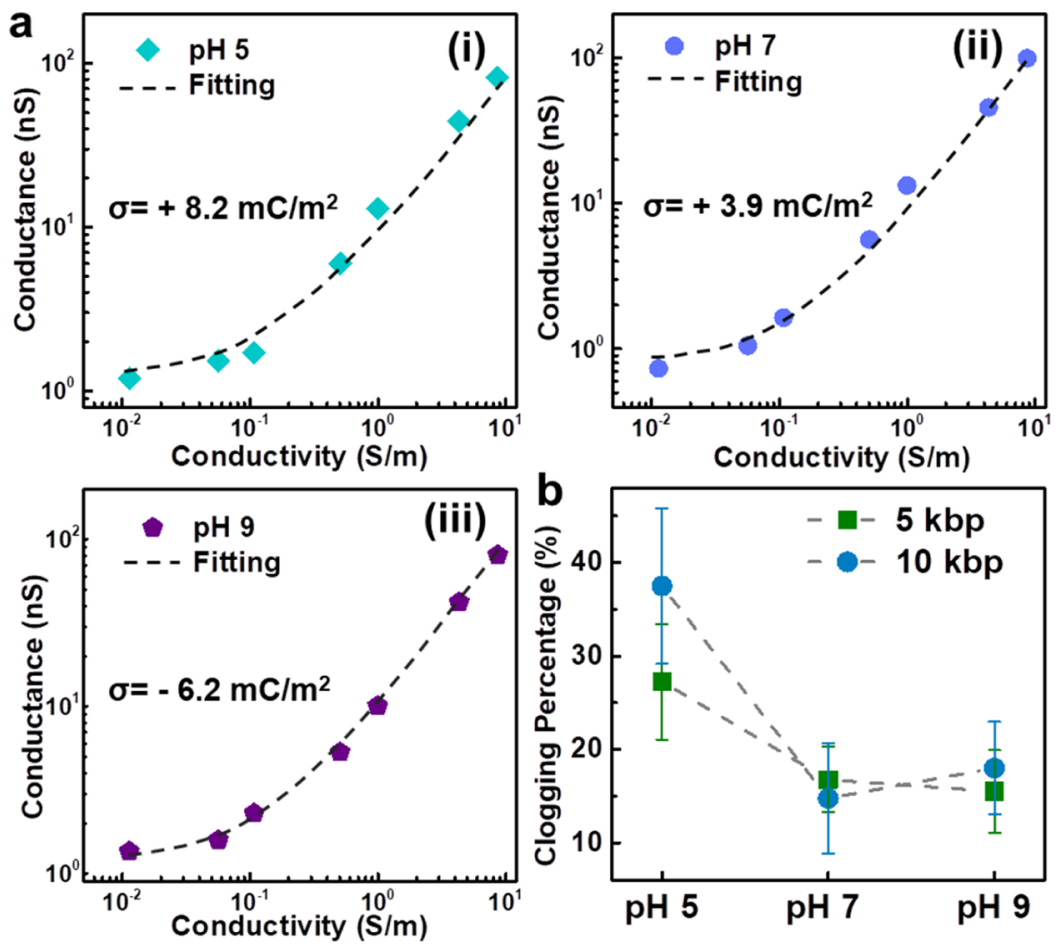

Figure 4. Effects of electrolyte $\mathrm{pH}$ on the nanopore surface charge and clogging probability. (a) Conductance vs conductivity relationship for single $\mathrm{HfO}_{2}$-coated nanopore at (i) $\mathrm{pH}=5$, (ii) $\mathrm{pH}=7$, and (iii) $\mathrm{pH}=9$. Fitting curves are marked as dashed lines. (b) Clogging percentage of $5 \mathrm{kbp}$ and $10 \mathrm{kbp}$ dsDNA in nanopore arrays at different $\mathrm{pH}$, at $200 \mathrm{mV}$ for $300 \mathrm{~s}$. Mean values and standard deviations from four independent experiments are presented.

magnitude of electrophoretic force will rise with increasing electric field strength, the shortened characteristic clogging lifetime at higher bias voltage is interpreted as a result of the stronger acting forces on the clogged DNA molecules. Hence, applying a strong reverse bias voltage may help exempt the pore being in the unstable clog state, as clogging from the opposite side is unlikely because of a substantially low concentration of DNA in the trans chamber. It was indeed observed in our experiments that some of the clogged pores could restitute to an unadulterated condition at a strong reverse bias.

Surface Charge Effect on Clogging Probability. To investigate whether the surface charge property of pore walls has an effect on the DNA clogging or not, the clogging behavior of $5 \mathrm{kbp}$ and $10 \mathrm{kbp}$ dsDNA in nanopore arrays at different electrolyte $\mathrm{pH}$ was studied. First, the surface charge density of the pore walls was characterized by measuring the conductance of single nanopores in electrolytes of different conductivities and then fitting the conductance versus conductivity data based on a well-established procedure. ${ }^{57,58}$ Details about the parameter extraction of both surface charge density and pore size are provided in the Supporting Information including Figures S5 and S6. The extracted surface charge density is $+8.2,+3.9$, and $-6.2 \mathrm{mC} / \mathrm{m}^{2}$ at $\mathrm{pH}$ of 5, 7, and 9, respectively; see Figure 4a.

The degree of clogging at different $\mathrm{pH}$ was evaluated based on a quantitative analysis of the pore clogging percentage after a $300 \mathrm{~s}$ optical observation at $200 \mathrm{mV}$. The average clogging percentage displayed in Figure $4 \mathrm{~b}$ for $5 \mathrm{kbp}$ and $10 \mathrm{kbp}$ dsDNA at pH 5 is 27.75 and $37.5 \%$, respectively, significantly higher than those $(15-20 \%)$ at $\mathrm{pH} 7$ and $\mathrm{pH} 9$. Because the more protonated surface at $\mathrm{pH} 5$ results in higher positive surface charge density, the negatively charged DNA molecules are exposed to a stronger electrostatic attraction force than that at $\mathrm{pH}$ 7. A higher possibility of clogging occurrence is anticipated. Similar effects have been reported for nanopores coated with organic substances; the more positively charged pores display longer DNA translocation dwell time, indicating a stronger electrostatic interaction between the negatively charged DNA and the pore surface. ${ }^{59}$ However, this simple charge polarity picture cannot fully explain the nearly identical clogging probability at $\mathrm{pH} 7$ and $\mathrm{pH}$ 9, as observed in Figure 4b. A further factor to consider is how the EOF and electrophoretic forces can collaboratively play in the DNApore interactions. It has been reported that EOF with an opposing direction to electrophoretic force can slow down the translocation speed of DNA molecules. ${ }^{60}$ In this regard, the chance for DNA molecules to interact with pore walls will increase. Thus, the hydrophobic interaction or van der Waals forces between DNA and pore surface may still lead to pore clogging. These findings suggest that the DNA clogging probability can be modulated by altering the electrolyte $\mathrm{pH}$, whereas it is affected by two distinct manners: (i) the strength of electrostatic attraction influenced by the surface charge density and (ii) the direction of EOF dragging force determined by the surface charge polarity.

Analytical Model. By referring to the previous theoretical studies, ${ }^{61,62}$ an analytical model is developed to account for the observed DNA clogging phenomenon during the translocation process. In the model, a dsDNA molecule translocates a positively charged conical pore in three basic steps: (i) the front segments of a translocating DNA strand enter the pore from its small opening (the cis side), (ii) the DNA segments transfer to the trans side and the pore is filled with the DNA, and (iii) the tail segments of the DNA strand exit from the pore. Because a translocating DNA may assume complex 

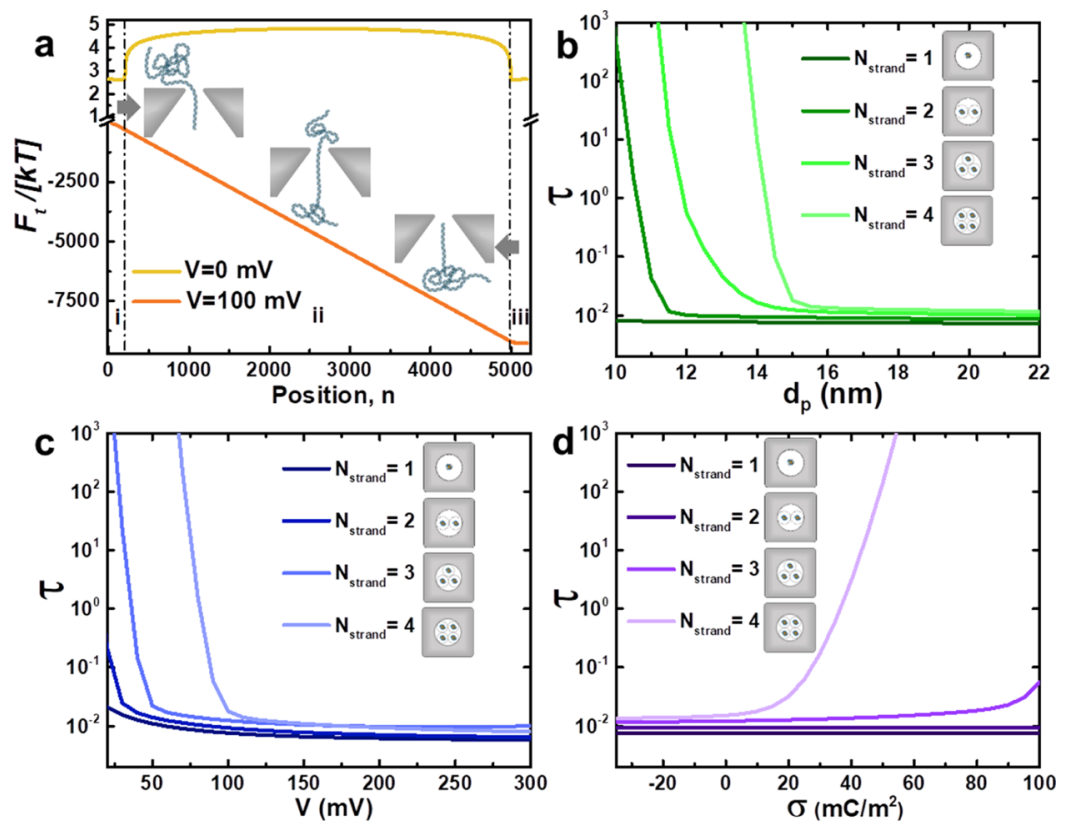

Figure 5. Evolvement of total energy during translocation and dependence of translocation time on a few representative parameters. (a) Energy landscape of DNA translocation at $V=0 \mathrm{mV}$ and at $V=100 \mathrm{mV}, M=200$ (corresponding to a pore length of $68 \mathrm{~nm}$ ), $N=5000$ (corresponding to $5 \mathrm{kbp}$ dsDNA), $d_{\mathrm{p}}=15 \mathrm{~nm}, \theta=54.7^{\circ}, \sigma=+10 \mathrm{mC} / \mathrm{m}^{2}$. Different regimes are denoted: (i) DNA entering the pore; (ii) DNA translocating across the pore; and (iii) DNA exiting from the pore. (b) $\tau$ as a function of $d_{\mathrm{p}}$ with different $N_{\text {strand }} V=50 \mathrm{mV}$, and $\sigma=+10 \mathrm{mC} / \mathrm{m}^{2}$. (c) $\tau$ as a function of $V$ with different $N_{\text {strand }}, d_{\mathrm{p}}=15 \mathrm{~nm}$, and $\sigma=+10 \mathrm{mC} / \mathrm{m}^{2}$. (d) $\tau$ as a function of $\sigma$ with different $N_{\text {strand }}, V=50 \mathrm{mV}$ and $d_{\mathrm{p}}=15 \mathrm{~nm}$.

configurations with folding or knotting, the model simplifies the translocating DNA strand as a bundle of different number of DNA strands (schematically illustrated in Figure S7 in the Supporting Information). By referring to the established models, ${ }^{61,62}$ the energy of the electric field-driven DNA translocation process is assumed to consist of four energy components: (i) conformational entropic energy of DNA $\left(F_{\mathrm{en}}\right)$, (ii) electric potential energy of DNA gained form the external electric field $\left(F_{\mathrm{el}}\right)$, (iii) electrostatic energy $\left(\varepsilon_{\mathrm{Q}}\right)$, and (iv) hydrophobic interaction energy $\left(\varepsilon_{\text {hy }}\right)$ between DNA and pore walls (details of mathematical derivation described in the Supporting Information). Therefore, the total energy $\left(F_{t}\right)$ of the translocating DNA is given by

$$
F_{\mathrm{t}}=F_{\mathrm{en}}+F_{\mathrm{el}}+\varepsilon_{\mathrm{Q}}+\varepsilon_{\mathrm{hy}}
$$

Typical $F_{\mathrm{t}}$ landscapes are compared in Figure 5a for a single dsDNA molecule of length $5 \mathrm{kbp}(N=5000)$ translocating in a conical pore with its small opening of diameter $d_{\mathrm{p}}=15 \mathrm{~nm}$ and surface charge density $\sigma=+10 \mathrm{mC} / \mathrm{m}^{2}$ but at bias voltage $V=$ $100 \mathrm{mV}$ versus $V=0 \mathrm{mV}$. At $V=0 \mathrm{mV}$ (without electrical driving force), the entropic energy dominates with a barrier height of $4.5 k T$. Hence, translocation is an unfavorable process because of loss in conformational entropy. At $V=100 \mathrm{mV}$, the electric potential energy dominates with an energy lowering along the translocation trajectory (details of energy landscape at intermediate bias provided in Figure S6). In both cases, the contribution from electrostatic and hydrophobic interaction between DNA and pore surface is negligible because of the large average distance between DNA and pore surface in the unfolded translocating configuration.

As discussed earlier, stronger DNA-pore interactions can lead to longer translocation dwell time for smaller nanopores (only allowing for unfolded translocations). In light of this scenario, the DNA translocation time is examined in our model to evaluate the level of DNA-pore interactions as an important indicator for the occurrence of DNA clogging. Based on the derived energy landscapes, the mean translocation time $(\tau)$ can be calculated with reflecting boundary conditions from the following equation ${ }^{61}$

$$
\tau=-\frac{1}{\kappa} \int_{0}^{N+M} \mathrm{~d} n \int_{0}^{n} \mathrm{~d} n^{\prime} \exp \frac{F_{\mathrm{t}}(n)}{k T}-\frac{F_{\mathrm{t}}\left(n^{\prime}\right)}{k T}
$$

where $\kappa$ is a phenomenological parameter denoting the local friction of the base pair. $\kappa=10^{6}$ is assumed in our calculations. For four types of translocation configurations with $N_{\text {strand }}$ to denote the number of bundled DNA strands, the calculated $\tau$ with different sets of parameters as a function of $d_{\mathrm{p}}, V$, and $\sigma$ is plotted in Figure $5 b-d$, respectively. It is apparent in Figure $5 b$ that for $d_{\mathrm{p}}>15 \mathrm{~nm}, \tau$ is only weakly dependent on $d_{\mathrm{p}}$ and $N_{\text {strand. }}$ In this regime, the situation is analogous to the translocation dominated by the field-driven drifting motion of DNA. For $N_{\text {strand }}>1$ and $d_{\mathrm{p}}<15 \mathrm{~nm}, \tau$ increases drastically at different threshold values of $d_{\mathrm{p}}$ for different $N_{\text {strand; }}$; smaller $d_{\mathrm{p}}$ allows for translocation of bundles with smaller $N_{\text {strand }}$, while bundles of a too large $N_{\text {strand }}$ can immediately clog as indicated by the sharp rises of the curves. Below the limit of direct clogging due to a too large $N_{\text {strand }}$, the observation of slower translocations for larger bundles (i.e., larger $N_{\text {strand }}$ ) is a result of the DNA-pore interactions that tend to slow down the ejection of the DNA from the pore. The DNA-pore interactions are stronger for larger $N_{\text {strand }}$ because of a combination of a larger number of interacting base pairs with a shorter average distance between DNA strands and pore walls. In brief, this model, despite its simplicity, appears to provide a good account of our experimental data regarding the clogging dependence on DNA length with a higher clogging probability for longer DNA molecules.

A slight decrease in $\tau$ with increasing $V$ above $100 \mathrm{mV}$ is seen in Figure $5 \mathrm{c}$ for all studied $N_{\text {strand }}$ indicating an unperturbed translocation driven predominantly by electro- 
phoresis in this regime. Significant increase of $\tau$ occurs below $100 \mathrm{mV}$ for $N_{\text {strand }}>1$, which is again caused by the strong DNA-pore interactions. Hence, DNA molecules are more prone to clog the pore at lower voltages for individual translocation events, which is consistent with the observed voltage-dependent lifetime of temporary clogging. On the other hand, this effect can be overwhelmed by the higher translocation frequency at higher voltage, see Figure 2, because within a fixed sampling time interval, the probability of pore clogging is codetermined by the clogging probability of individual translocation events and the translocation frequency.

How $\tau$ would vary with $\sigma$ is illustrated in Figure 5d. For unfolded $\left(N_{\text {strand }}=1\right)$ and double-folded $\left(N_{\text {strand }}=2\right)$ configurations, $\tau$ stays nearly constant in the excessively wide range of $\sigma$ from -20 to $+100 \mathrm{mC} / \mathrm{m}^{2}$. For $N_{\text {strand }}=3, \tau$ increases noticeably with $\sigma$ above $+80 \mathrm{mC} / \mathrm{m}^{2}$, while for $N_{\text {strand }}$ $=4, \tau$ increases sharply with $\sigma$ above $+10 \mathrm{mC} / \mathrm{m}^{2}$. The electrostatic interaction between DNA and pore walls is obviously insignificant for the translocation of unfolded and double-folded DNA strands, but governs for that of thicker bundles of DNA strands. In short, a stronger electrostatic interaction at higher surface charge density will lead to a higher probability of clogging for multifolded or knotted DNA molecules, supporting the preceding experimental observations of a higher clogging percentage at lower $\mathrm{pH}$ of 5 with a measured higher surface charge density than that at $\mathrm{pH} 7$.

\section{CONCLUSIONS}

The dynamics of dsDNA clogging in $\mathrm{HfO}_{2}$ nanopores have been systematically investigated using real-time optical observation. By combining a wafer-scale method of fabricating Si nanopore arrays and ALD coating of a highly stable $\mathrm{HfO}_{2}$ layer, sub-20 nm PL-free nanopore arrays that enable parallelized visualization and reliable determination of DNA clogging events were realized. The real-time characterization reveals that the probability of pore clogging increases with the length of DNA strands and applied bias voltage. The dependence on DNA length can be accounted for by invoking an increased probability of knotting and folding with longer DNA strands, while that on bias is attributed to more frequent translocation events at higher voltage. Additionally, the surface charge on pore walls shows a prominent effect on the probability of DNA clogging through electrostatic attraction and induced EOF. The observed clogging behavior can be well explained by a simple analytical model, where translocation time is employed to evaluate the degree of DNA-pore interactions, which supports the discussion of complex configurations of translocating DNA strands and electrostatic attractions as the root cause. From an application perspective, the occurrence of DNA clogging need be minimized to enable a reliable and prolonged DNA sensing with SSNPs. The presented results shed lights on the DNA clogging phenomenon and can be useful for outlining measures to prevent pore clogging in SSNP-based sensing.

\section{ASSOCIATED CONTENT}

\section{SI Supporting Information}

The Supporting Information is available free of charge at https://pubs.acs.org/doi/10.1021/acs.jpcb.0c07756.

Schematic nanopore setup for real-time optical observation; schematic of the process flow for the fabrication of nanopore arrays; histogram of the small opening diameter of the nanopore arrays; illustration and the optical images of the fluidic cell setup; $I-V$ characteristics of single nanopores in $\mathrm{KCl}$ solutions of different concentrations at various $\mathrm{pH}$; energy landscape of DNA translocation at external bias at $0-100 \mathrm{mV}$ with a constant step of $10 \mathrm{mV}$; model to calculate the surface charge density; analytical model to calculate the free energy of translocating DNA; and video clips of realtime observation of DNA clogging at different voltages (PDF)

$200 \mathrm{mV} 10 \mathrm{kbp}$ (MP4)

$400 \mathrm{mV} 10 \mathrm{kbp}(\mathrm{MP} 4)$

$600 \mathrm{mV} \_10 \mathrm{kbp}(\mathrm{MP} 4)$

\section{AUTHOR INFORMATION}

\section{Corresponding Author}

Shi-Li Zhang - Department of Electrical Engineering, Division of Solid-State Electronics, Uppsala University, SE-751 03

Uppsala, Sweden; Phone: +46 18 4717247;

Email: shili.zhang@angstrom.uu.se

\section{Authors}

Shiyu Li - Department of Electrical Engineering, Division of Solid-State Electronics, Uppsala University, SE-751 03 Uppsala, Sweden; ○ orcid.org/0000-0003-4948-8353

Shuangshuang Zeng - Department of Electrical Engineering, Division of Solid-State Electronics, Uppsala University, SE75103 Uppsala, Sweden; (1) orcid.org/0000-0002-75846479

Chenyu Wen - Department of Electrical Engineering, Division of Solid-State Electronics, Uppsala University, SE-751 03 Uppsala, Sweden; 이이.org/0000-0003-4395-7905

Laurent Barbe - Department of Material Science and Engineering, Division of Microsystem Technology, Uppsala University, SE-751 21 Uppsala, Sweden

Maria Tenje - Department of Material Science and Engineering, Division of Microsystem Technology, Uppsala University, SE-751 21 Uppsala, Sweden

Zhen Zhang - Department of Electrical Engineering, Division of Solid-State Electronics, Uppsala University, SE-751 03 Uppsala, Sweden; 이이.org/0000-0003-4317-9701

Klas Hjort - Department of Material Science and Engineering, Division of Microsystem Technology, Uppsala University, SE75121 Uppsala, Sweden

Complete contact information is available at:

https://pubs.acs.org/10.1021/acs.jpcb.0c07756

\section{Notes}

The authors declare no competing financial interest.

\section{ACKNOWLEDGMENTS}

This work was partially supported by the Swedish Research Council (2014-6300 and 2018-03494) and a scholarship to Shiyu Li (201606100043) from the China Scholarship Council (CSC).

\section{REFERENCES}

(1) Venkatesan, B. M.; Bashir, R. Nanopore Sensors for Nucleic Acid Analysis. Nat. Nanotechnol. 2011, 6, 615-624.

(2) Varongchayakul, N.; Song, J.; Meller, A.; Grinstaff, M. W. SingleMolecule Protein Sensing in a Nanopore: a Tutorial. Chem. Soc. Rev. 2018, 47, 8512-8524. 
(3) Shi, W.; Friedman, A. K.; Baker, L. A. Nanopore Sensing. Anal. Chem. 2017, 89, 157-188.

(4) Wen, C.; Zhang, S.-L. Fundamentals and Potentials of SolidState Nanopores: A Review. J. Phys. D: Appl. Phys. 2020, 54, 023001.

(5) McNally, B.; Singer, A.; Yu, Z.; Sun, Y.; Weng, Z.; Meller, A. Optical Recognition of Converted DNA Nucleotides for SingleMolecule DNA Sequencing Using Nanopore Arrays. Nano Lett. 2010, 10, 2237-2244.

(6) Wang, R.; Gilboa, T.; Song, J.; Huttner, D.; Grinstaff, M. W.; Meller, A. Single-Molecule Discrimination of Labeled DNAs and Polypeptides Using Photoluminescent-Free $\mathrm{TiO}_{2}$ Nanopores. ACS Nano 2018, 12, 11648-11656.

(7) Chuah, K.; Wu, Y. F.; Vivekchand, S. R. C.; Gaus, K.; Reece, P. J.; Micolich, A. P.; Gooding, J. J. Nanopore Blockade Sensors for Ultrasensitive Detection of Proteins in Complex Biological Samples. Nat. Commun. 2019, 10, 2109.

(8) Jonsson, M. P.; Dekker, C. Plasmonic Nanopore for Electrical Profiling of Optical Intensity Landscapes. Nano Lett. 2013, 13, 10291033.

(9) Ren, R.; Zhang, Y.; Nadappuram, B. P.; Akpinar, B.; Klenerman, D.; Ivanov, A. P.; Edel, J. B.; Korchev, Y. Nanopore Extended FieldEffect Transistor for Selective Single-Molecule Biosensing. Nat. Commun. 2017, 8, 586.

(10) Ren, R.; Wang, X.; Cai, S.; Zhang, Y.; Korchev, Y.; Ivanov, A. P.; Edel, J. B. Selective Sensing of Proteins Using Aptamer Functionalized Nanopore Extended Field-Effect Transistors. Small Methods 2020, 4, 2000356.

(11) Gilboa, T.; Meller, A. Optical Sensing and Analyte Manipulation in Solid-State Nanopores. Analyst 2015, 140, 47334747.

(12) Dekker, C. Solid-State Nanopores. Nat. Nanotechnol. 2007, 2, 209-215.

(13) Haque, F.; Li, J.; Wu, H.-C.; Liang, X.-J.; Guo, P. Solid-State and Biological Nanopore for Real-Time Sensing of Single Chemical and Sequencing of DNA. Nano Today 2013, 8, 56-74.

(14) Eggenberger, O. M.; Ying, C.; Mayer, M. Surface Coatings for Solid-state Nanopores. Nanoscale 2019, 11, 19636-19657.

(15) Hlady, V.; Buijs, J. Protein Adsorption on Solid Surfaces. Curr. Opin. Biotechnol. 1996, 7, 72-77.

(16) Powell, M. R.; Cleary, L.; Davenport, M.; Shea, K. J.; Siwy, Z. S. Electric-Field-Induced Wetting and Dewetting in Single Hydrophobic Nanopores. Nat. Nanotechnol. 2011, 6, 798-802.

(17) Schneider, G. F.; Xu, Q.; Hage, S.; Luik, S.; Spoor, J. N. H.; Malladi, S.; Zandbergen, H.; Dekker, C. Tailoring the Hydrophobicity of Graphene for Its Use as Nanopores for DNA Translocation. Nat. Commun. 2013, 4, 2619.

(18) Siwy, Z.; Kosińska, I. D.; Fuliński, A.; Martin, C. R. Asymmetric Diffusion Through Synthetic Nanopores. Phys. Rev. Lett. 2005, 94, 048102.

(19) Fologea, D.; Uplinger, J.; Thomas, B.; McNabb, D. S.; Li, J. Slowing DNA Translocation in A Solid-State Nanopore. Nano Lett. 2005, 5, 1734-1737.

(20) Sparreboom, W.; van den Berg, A.; Eijkel, J. C. T. Principles and Applications of Nanofluidic Transport. Nat. Nanotechnol. 2009, 4, 713-720.

(21) Narayanan, S.; Fedorov, A. G.; Joshi, Y. K. Interfacial Transport of Evaporating Water Confined in Nanopores. Langmuir 2011, 27, 10666-10676.

(22) Li, X.; Hu, R.; Li, J.; Tong, X.; Diao, J. J.; Yu, D.; Zhao, Q. NonSticky Translocation of Biomolecules through Tween 20 Coated Solid-State Nanopores in A Wide pH Range. Appl. Phys. Lett. 2016, 109, 143105.

(23) Xie, Y.; Xue, J.; Wang, L.; Wang, X.; Jin, K.; Chen, L.; Wang, Y. Surface Modification of Single Track-Etched Nanopores with Surfactant CTAB. Langmuir 2009, 25, 8870-8874.

(24) Giamblanco, N.; Coglitore, D.; Janot, J.-M.; Coulon, P. E.; Charlot, B.; Balme, S. Detection of Protein Aggregate Morphology through Single Antifouling Nanopore. Sens. Actuators, B 2018, 260, 736-745.
(25) Siwy, Z.; Trofin, L.; Kohli, P.; Baker, L. A.; Trautmann, C.; Martin, C. R. Protein Biosensors Based on Biofunctionalized Conical Gold Nanotubes. J. Am. Chem. Soc. 2005, 127, 5000-5001.

(26) Emilsson, G.; Xiong, K.; Sakiyama, Y.; Malekian, B.; Ahlberg Gagnér, V.; Schoch, R. L.; Lim, R. Y. H.; Dahlin, A. B. Polymer Brushes in Solid-State Nanopores Form An Impenetrable Entropic Barrier for Proteins. Nanoscale 2018, 10, 4663-4669.

(27) Yusko, E. C.; Bruhn, B. R.; Eggenberger, O. M.; Houghtaling, J.; Rollings, R. C.; Walsh, N. C.; Nandivada, S.; Pindrus, M.; Hall, A. R.; Sept, D.; et al. Real-Time Shape Approximation and Fingerprinting of Single Proteins Using a Nanopore. Nat. Nanotechnol. 2017, $12,360-367$

(28) Yusko, E. C.; Johnson, J. M.; Majd, S.; Prangkio, P.; Rollings, R. C.; Li, J.; Yang, J.; Mayer, M. Controlling Protein Translocation through Nanopores with Bio-inspired Fluid Walls. Nat. Nanotechnol. 2011, 6, 253-260.

(29) Roelen, Z.; Bustamante, J. A.; Carlsen, A.; Baker-Murray, A.; Tabard-Cossa, V. Instrumentation for Low Noise Nanopore-Based Ionic Current Recording under Laser Illumination. Rev. Sci. Instrum. 2018, 89, 015007.

(30) Wanunu, M.; Meller, A. Single-Molecule Analysis of Nucleic Acids and DNA-Protein Interactions Using Nanopores. SingleMolecule Techniques: A Laboratory Manual; Cold Spring Harbor Press: New York, 2008; pp 395-420.

(31) Kurz, V.; Nelson, E. M.; Shim, J.; Timp, G. Direct Visualization of Single-Molecule Translocations through Synthetic Nanopores Comparable in Size to a Molecule. ACS Nano 2013, 7, 4057-4069.

(32) Ando, G.; Hyun, C.; Li, J.; Mitsui, T. Directly Observing the Motion of DNA Molecules near Solid-State Nanopores. ACS Nano 2012, 6, 10090-10097.

(33) Kubota, T.; Lloyd, K.; Sakashita, N.; Minato, S.; Ishida, K.; Mitsui, T. Clog and Release, and Reverse Motions of DNA in a Nanopore. Polymers 2019, 11, 84.

(34) Assad, O. N.; Di Fiori, N.; Squires, A. H.; Meller, A. Two Color DNA Barcode Detection in Photoluminescence Suppressed Silicon Nitride Nanopores. Nano Lett. 2015, 15, 745-752.

(35) Zhmud, B. V.; Bergström, L. Dissolution Kinetics of Silicon Nitride in Aqueous Suspension. J. Colloid Interface Sci. 1999, 218, $582-584$.

(36) Rollings, R.; Graef, E.; Walsh, N.; Nandivada, S.; Benamara, M.; Li, J. The Effects of Geometry and Stability of Solid-State Nanopores on Detecting Single DNA Molecules. Nanotechnology 2015, 26, 044001.

(37) Chou, Y.-C.; Masih Das, P.; Monos, D. S.; Drndić, M. Lifetime and Stability of Silicon Nitride Nanopores and Nanopore Arrays for Ionic Measurements. ACS Nano 2020, 14, 6715-6728.

(38) van den Hout, M.; Hall, A. R.; Wu, M. Y.; Zandbergen, H. W.; Dekker, C.; Dekker, N. H. Controlling Nanopore Size, Shape and Stability. Nanotechnology 2010, 21, 115304.

(39) Vogt, M.; Hauptmann, R. Plasma-Deposited Passivation Layers for Moisture and Water Protection. Surf. Coat. Technol. 1995, 74-75, 676-681.

(40) Yamazaki, H.; Hu, R.; Zhao, Q.; Wanunu, M. Photothermally Assisted Thinning of Silicon Nitride Membranes for Ultrathin Asymmetric Nanopores. ACS Nano 2018, 12, 12472-12481.

(41) Shim, J.; Rivera, J. A.; Bashir, R. Electron Beam Induced Local Crystallization of $\mathrm{HfO}_{2}$ Nanopores for Biosensing Applications. Nanoscale 2013, 5, 10887-10893.

(42) Larkin, J.; Henley, R.; Bell, D. C.; Cohen-Karni, T.; Rosenstein, J. K.; Wanunu, M. Slow DNA Transport through Nanopores in Hafnium Oxide Membranes. ACS Nano 2013, 7, 10121-10128.

(43) Zeng, S.; Wen, C.; Solomon, P.; Zhang, S.-L.; Zhang, Z. Rectification of Protein Translocation in Truncated Pyramidal Nanopores. Nat. Nanotechnol. 2019, 14, 1056-1062.

(44) Zeng, S.; Li, S.; Utterström, J.; Wen, C.; Selegård, R.; Zhang, S.L.; Aili, D.; Zhang, Z. Mechanism and Kinetics of Lipid Bilayer Formation in Solid-State Nanopores. Langmuir 2020, 36, 1446-1453.

(45) Khoshman, J. M.; Kordesch, M. E. Optical Properties of a-HfO Thin Films. Surf. Coat. Technol. 2006, 201, 3530-3535. 
(46) Cohen, M. L.; Chelikowsky, J. R. Electronic Structure and Optical Properties of Semiconductors; Springer-Verlag Berlin Heidelberg, 2012; Vol. 75.

(47) Zhang, M.; Ngampeerapong, C.; Redin, D.; Ahmadian, A.; Sychugov, I.; Linnros, J. Thermophoresis-Controlled Size-Dependent DNA Translocation through an Array of Nanopores. ACS Nano 2018, $12,4574-4582$.

(48) Larkin, J.; Henley, R. Y.; Jadhav, V.; Korlach, J.; Wanunu, M. Length-Independent DNA Packing into Nanopore Zero-Mode Waveguides for Low-Input DNA Sequencing. Nat. Nanotechnol. 2017, 12, 1169-1175.

(49) Bell, N. A. W.; Muthukumar, M.; Keyser, U. F. Translocation Frequency of Double-Stranded DNA through a Solid-State Nanopore. Phys. Rev. E 2016, 93, 022401.

(50) Wanunu, M.; Sutin, J.; McNally, B.; Chow, A.; Meller, A. DNA Translocation Governed by Interactions with Solid-State Nanopores. Biophys. J. 2008, 95, 4716-4725.

(51) van den Hout, M.; Krudde, V.; Janssen, X. J. A.; Dekker, N. H. Distinguishable Populations Report on the Interactions of Single DNA Molecules with Solid-State Nanopores. Biophys. J. 2010, 99, 3840-3848.

(52) Kumar Sharma, R.; Agrawal, I.; Dai, L.; Doyle, P. S.; Garaj, S. Complex DNA Knots Detected with a Nanopore Sensor. Nat. Commun. 2019, 10, 4473.

(53) Plesa, C.; Verschueren, D.; Pud, S.; van der Torre, J.; Ruitenberg, J. W.; Witteveen, M. J.; Jonsson, M. P.; Grosberg, A. Y.; Rabin, Y.; Dekker, C. Direct Observation of DNA Knots Using a Solid-State Nanopore. Nat. Nanotechnol. 2016, 11, 1093-1097.

(54) Steinbock, L. J.; Otto, O.; Chimerel, C.; Gornall, J.; Keyser, U. F. Detecting DNA Folding with Nanocapillaries. Nano Lett. 2010, 10, 2493-2497.

(55) Wanunu, M.; Morrison, W.; Rabin, Y.; Grosberg, A. Y.; Meller, A. Electrostatic Focusing of Unlabelled DNA into Nanoscale Pores Using a Salt Gradient. Nat. Nanotechnol. 2010, 5, 160-165.

(56) Kosmulski, M. Isoelectric Points and Points of Zero Charge of Metal (Hydr) Oxides: 50 Years after Parks' Review. Adv. Colloid Interface Sci. 2016, 238, 1-61.

(57) Smeets, R. M. M.; Keyser, U. F.; Krapf, D.; Wu, M.-Y.; Dekker, N. H.; Dekker, C. Salt Dependence of Ion Transport and DNA Translocation through Solid-State Nanopores. Nano Lett. 2006, 6, 89-95.

(58) Wen, C.; Zhang, Z.; Zhang, S.-L. Physical Model for Rapid and Accurate Determination of Nanopore Size via Conductance Measurement. ACS Sens. 2017, 2, 1523-1530.

(59) Anderson, B. N.; Muthukumar, M.; Meller, A. pH Tuning of DNA Translocation Time through Organically Functionalized Nanopores. ACS Nano 2013, 7, 1408-1414.

(60) Di Fiori, N.; Squires, A.; Bar, D.; Gilboa, T.; Moustakas, T. D.; Meller, A. Optoelectronic Control of Surface Charge and Translocation Dynamics in Solid-state Nanopores. Nat. Nanotechnol. 2013, 8, 946-951.

(61) Muthukumar, M. Polymer Escape through a Nanopore. J. Chem. Phys. 2003, 118, 5174-5184.

(62) Muthukumar, M. Polymer Translocation; Taylor \& Francis: Boca Raton, 2011. 